\title{
Repeated Exposure to Hyperbaric Hyperoxia Affects Mitochondrial Functions of the Lung Fibroblasts
}

\author{
J. DEJMEK ${ }^{1,2,3^{*}}$, M. KOHOUTOVÄ ${ }^{2,4^{*}}$, M. KRIPNEROVÁ ${ }^{5^{*}}$, M. ČEDÍKOVÁ ${ }^{2,4}$, Z. TƯMA $^{2}$, \\ V. BABUŠKA ${ }^{6}$, L. BOLEK ${ }^{2,3}$, J. KUNCOVÁ ${ }^{2,3,4}$ \\ ${ }^{*}$ These authors contributed equally to the study.
}

${ }^{1}$ Department of Medical Biophysics, Faculty of Medicine and Dentistry, Palacký University, Olomouc, Czech Republic, ${ }^{2}$ Biomedical Centre, Faculty of Medicine in Plzeň, Charles University, Plzeň, Czech Republic, ${ }^{3}$ Institute of Biophysics, Faculty of Medicine in Plzeň, Charles University, Plzeň, Czech Republic, ${ }^{4}$ Institute of Physiology, Faculty of Medicine in Plzeň, Charles University, Plzeň, Czech Republic, ${ }^{5}$ Institute of Biology, Faculty of Medicine in Plzeň, Charles University, Plzeň, Czech Republic, ${ }^{6}$ Institute of Medical Chemistry and Biochemistry, Faculty of Medicine in Plzeň, Charles University, Plzeň, Czech Republic

Received March 24, 2018

Accepted September 12, 2018

\section{Summary}

Hyperbaric oxygen (HBO) therapy, i.e. breathing pure oxygen under increased environmental pressures serves as a treatment for diverse medical conditions. However, elevated oxygen concentration can be detrimental to central nervous system or lungs. Our study aimed to evaluate the effects of repeated exposure to $\mathrm{HBO}$ on mitochondrial respiration assessed by highresolution respirometry (HRR), cell viability estimated by PrestoBlue ${ }^{\circ}$ reaction, morphology analyzed by routine phase contrast and fluorescent microscopy, and superoxide dismutase (SOD) and citrate synthase (CS) activities using human lung fibroblasts. The cells were exposed to HBO for $2 \mathrm{~h}$ per day for 5 consecutive days. One day after the last exposure, HBO cells displayed significantly smaller area and perimeter, compromised viability and elevated SOD activity. No changes were detected in CS activity or quality of mitochondrial network. HRR revealed impaired mitochondrial oxygen consumption manifested by increased leak respiration, decreased activity of complex II and compromised ATP-related oxygen consumption when fatty acids were oxidized. Our findings document that in conditions mimicking chronic intermittent exposure to $\mathrm{HBO}$, lung fibroblasts suffer from compromised mitochondrial respiration linked to complex II and impaired cellular growth in spite of increased antioxidant defense. Underlying mechanism of this HBO-induced mitochondrial dysfunction should be further explored.

\section{Key words}

Hyperbaric hyperoxia • High resolution respirometry • Human fetal lung fibroblasts • Mitochondria • Superoxide dismutase

\section{Corresponding author}

J. Kuncová, Institute of Physiology, Faculty of Medicine in Plzeň, Charles University, Alej Svobody 76, 32300 Plzeň, Czech Republic. E-mail: jitka.kuncova@Ifp.cuni.cz

\section{Introduction}

Hyperbaric oxygen (HBO) therapy, i.e. breathing $100 \%$ oxygen at environmental pressures greater than 1 atmosphere absolute (ATA) in an airtight chamber serves as a primary or adjunctive treatment for diverse medical conditions. Increased hydrostatic pressure per se helps to treat diseases associated with presence of gas bubbles in vessels and tissues (decompression sickness or gas embolism; Camporesi and Bosco 2014, Moon 2014). Majority of medical indications of $\mathrm{HBO}$ therapy is related to improved oxygen delivery to tissues caused by increased quantity of oxygen dissolved in plasma. HBO therapy is widely recommended in the treatment of chronic and acute non-healing wounds and ulcers (Brem and Tomic-Canic 2007, Schreml et al. 2010), post-radiation damage (Borab 
et al. 2017), necrotizing soft tissue infections (Wilkinson and Doolette 2004), spinal cord injury (Patel and Huang 2017), and carbon monoxide poisoning (Huang et al. 2017). Although beneficial effects of HBO have been documented in a number of double-blind controlled randomized studies, meta-analyses of trials focused on individual indications questioned their design, analysis, and conclusions pointing out the increased risk of bias and methodological flaws (Bennett et al. 2012, Buckley et al. 2011, Yang et al. 2015, Zhao et al. 2017). In addition, numerous studies indicated more or less serious adverse side effects of HBO caused by either high pressure or high oxygen concentration. Increased pressure can cause middle ear or pulmonary barotrauma ( $\mathrm{Ng}$ et al. 2017, Rivalland et al. 2010). Elevated oxygen concentration can be detrimental to central nervous system, lung (Rabrenović et al. 2015) or could be related to rare ocular complications (McMonnies 2015).

At the cellular and subcellular levels, HBO therapy is known to increase production of reactive oxygen and nitrogen species (RONS), which may account for both beneficial and potentially toxic effects of HBO (Poff et al. 2016). Increased production of RONS stimulates expression of genes related to defense against oxidative stress (Matsunami et al. 2009), might be involved in induction of mitophagy (Han et al. 2017), suppresses MAPK signaling and mitochondrial apoptotic pathway (Niu et al. 2013), and could be implicated in stimulation of angiogenesis, proliferation and differentiation of mesenchymal stem cells (Lin et al. 2014).

Studies concerning mitochondrial oxygen consumption in HBO conditions are surprisingly rare reporting increased, decreased or unchanged mitochondrial respiration or enzymatic activity of individual respiratory complexes in various organs, tissues and cells (Bassett and Fisher 1979, Tolentino et al. 2006).

In this study, we investigated the effects of repeated exposure to HBO on mitochondrial respiration, cell viability, morphology, and superoxide dismutase (SOD) activity using human lung fibroblasts. Our findings document that in conditions mimicking chronic intermittent exposure to $\mathrm{HBO}$, lung fibroblasts suffer from impaired mitochondrial respiration linked to complex II activity and diminished increase in the cell mass in spite of increased antioxidant defense.

\section{Methods}

\section{Microhypebaric chamber $\mathrm{H} H \mathrm{BK} 2$}

Microhyperbaric chamber (uHBK2) is a unique biophysical reactor developed in cooperation of Palacky University in Olomouc and Charles University in Prague. The device (internal volume 0.51 ) enables elevation of the pressure inside the chamber up to $15 \mathrm{MPa}$, change in the composition of the atmosphere, and precise regulation of the internal temperature.

\section{Chemicals}

If not stated otherwise, all chemicals, antibodies, SOD activity assay kits, and cell culture plastics were purchased from Sigma-Aldrich, Prague, CZ.

\section{Cell culture and precultivation}

Cell line was obtained from ATCC (American type culture collection, Rockville, Maryland, USA) and cultured in accordance with ATCC recommendations. Human fetal lung fibroblasts (HFL1) were cultivated in F12K Medium supplemented with $10 \%$ (v/v) fetal bovine serum, $100 \mathrm{U} / \mathrm{ml}$ penicillin and $100 \mathrm{mg} / \mathrm{ml}$ streptomycin (all from PAA Laboratories $\mathrm{GmbH}$, Pasching, Austria), and $2.5 \mathrm{mmol} / 1 \mathrm{~L}$-glutamine (Gibco, Life Technologies, Paisley, UK) at $37{ }^{\circ} \mathrm{C}$ under $5 \% \mathrm{CO}_{2}$ in a humidified incubator. For subculturing, cells were washed with phosphate-buffered saline (PBS) and then briefly incubated with $0.05 \%$ trypsin/ $0.02 \%$ EDTA in PBS.

\section{Cell treatment}

For hyperbaric oxygen exposure, HBO cells were exposed to hyperbaric hyperoxia for two hours per day for five consecutive days in microhyperbaric chamber flooded with $5 \mathrm{kPa} \mathrm{CO}_{2}$ and $295 \mathrm{kPa} \mathrm{O}_{2}$. During exposure, temperature inside the chamber was maintained at $37{ }^{\circ} \mathrm{C}$ and relative humidity at $100 \%$. After each exposure, cells were returned in a humidified incubator and were further cultured at $37^{\circ} \mathrm{C}$ in humidified air with $5 \% \mathrm{CO}_{2}$.

The control cells were maintained in normobaric conditions (air $+5 \% \mathrm{CO}_{2}$ ) continuously.

\section{Cell growth analysis}

Cells were seeded at 15,000 per well in the 24-well TPP ${ }^{\circledR}$ tissue culture and exposed to HBO or control conditions as described above. Cell growth rates were measured daily over a period of 6 days using the 
Bürker hemocytometer method. Cell density was expressed in number of cells per $1 \mathrm{ml}$.

\section{Cell viability}

Cell viability after repeated short-term exposure to $\mathrm{HBO}$ was determined by PrestoBlue ${ }^{\circledR}$ viability reagent (Invitrogen, Life Technologies, Prague, CZ) following manufacturer's instructions. The reagent uses mitochondrial activity to reduce the nonfluorescent blue resazurin to the fluorescent pink resorufin. Cells were seeded into 96-well plate in concentration 10,000 cells per well. The bottom-read fluorescence was determined at $560 \mathrm{~nm}$ (excitation) and $590 \mathrm{~nm}$ (emission) after 10 min incubation using microplate reader Synergy H1 (Biotek, Winooski, Vermont, USA).

\section{Cell morphology analysis}

Basic morphological evaluation was carried out by routine phase contrast microscopic observation by two independent observers in $59 \mathrm{HBO}$ and 55 control cells. Briefly, phase contrast photos of growing cells were taken at a $60 \times$ magnification by the Hamamatsu Orca-ER camera mounted on the Olympus IX 81 inverted microscope (Olympus, Tokyo, Japan). The QuickPHOTO Industrial 2.3 software (Promicra Ltd., Prague, CZ) was used for the photo evaluations. The area and perimeter of HFL1 cells were calculated based on the polygon surface created by tracing the contours of cells (Holubova et al. 2012). The circularity index was calculated as $4 \pi \times($ area/perimeter squared $)$.

\section{Indirect immunofluorescence}

HFL1 cells were seeded in count 40,000 per well on the bottom of 12-well plate and treated as described above. For further processing, Image-iT $\AA$ Fixation/Permeabilization Kit (Life Technologies, Prague, CZ) was used. Samples were fixed with $4 \%$ formaldehyde for $15 \mathrm{~min}$, permeabilized in Permeabilization solution for $15 \mathrm{~min}$ and blocked in $3 \%$ BSA for $60 \mathrm{~min}$. Cells were then sequentially incubated overnight with the primary monoclonal Anti-Vinculin (V9131) and monoclonal Anti-Vimentin (V5255) antibodies. Secondary Anti-Mouse IgG-Atto 488 goat antibody (62197) and Anti-Mouse IgM-FITC goat antibody (F9259) were applied for $60 \mathrm{~min}$ at room temperature in dark. For actin staining, Phalloidin-Atto 488 (49409) was used. Samples were mounted in ProLong Gold antifade reagent with DAPI (Invitrogen, Life Technologies, Prague, CZ) and analyzed using the
Olympus IX81 fluorescent microscope (Olympus; Tokyo, Japan) equipped with a Cell-R system at $40 \times, 100 \times$, and $400 \times$ magnification.

Cellular mitochondrial network was visualized with MitoTrackerTM Red CMXRos (No. M7512; Thermo Fisher Scientific, Prague, CZ) using $0.5 \mu \mathrm{l}$ of $1 \mathrm{mmol} / 1$ stain for each well containing $1 \mathrm{ml}$ of the cell culture medium. Basic evaluation was followed by fluorescent microscopy at a $100 \times$ magnification by the Hamamatsu Orca-ER camera mounted on the Olympus IX 81 inverted microscope (Olympus; Tokyo, Japan).

\section{High-resolution respirometry}

HBO $(n=7)$ and control cells $(n=15)$ were seeded at 400,000 per $90 \mathrm{~mm}$ Petri dish, suspended in $10 \mathrm{ml}$ F12K, treated as described previously and harvested. Respirometric experiments were performed in $2 \mathrm{ml}$ glass chambers of the Oxygraph2k (Oroboros, Innsbruck, Austria) at $37{ }^{\circ} \mathrm{C}$. Oxygen consumption was measured in MIR05 medium $(0.5 \mathrm{mmol} / 1$ ethylene glycol tetraacetic acid, $3 \mathrm{mmol} / 1 \mathrm{MgCl}_{2} \cdot 6 \mathrm{H}_{2} \mathrm{O}, 60 \mathrm{mmol} / 1 \mathrm{~K}$-lactobionate, $20 \mathrm{mmol} / 1$ taurine, $10 \mathrm{mmol} / 1 \quad \mathrm{KH}_{2} \mathrm{PO}_{4}, \quad 20 \mathrm{mmol} / 1$ HEPES, $110 \mathrm{mmol} / 1$ D-sucrose and $1 \mathrm{~g} / \mathrm{l}$ albumin essentially fatty acid free) equilibrated with air (Pesta and Gnaiger 2012). The cells were injected into the chambers, mixed and counted using Bürker hemocytometer. The average cell count was $\sim 5 \times 10^{5}$ cells per chamber. After the chambers were closed, respiratory activity of intact cells was assessed as routine respiration (ROUT). Then, the cell membrane was permeabilized with digitonin $(5 \mu \mathrm{g} / \mathrm{ml})$ and combination of substrates, inhibitors and uncouplers was sequentially injected into the chambers to determine the following respiratory states: Non-phosphorylating LEAK state (L; oxygen consumption needed for electron transport compensating for proton leak across the inner mitochondrial membrane) was induced by addition of substrates providing electrons to complex I (malate, $2 \mathrm{mmol} / \mathrm{l}$ ) and electron-transferring flavoprotein (ETF; palmitoylcarnitine, $20 \mu \mathrm{mol} / \mathrm{l}$ ); state OXPHOS(Pal) (P(Pal); active phosphorylating respiration) was induced by adenosine diphosphate (ADP, $5 \mathrm{mmol} / \mathrm{l})$. Then, the degree of cell membrane permeabilization was verified with cytochrome c (10 $\mu \mathrm{mol} / \mathrm{l})$. Mitochondrial respiration was then increased by complex I substrates glutamate $(10 \mathrm{mmol} / \mathrm{l}$; OXPHOS(PalG)) and pyruvate (5 mmol/1; OXPHOS(PalGP)). OXPHOS(PalGPS) was induced by succinate, a complex II substrate (10 mmol/l); ETS(PalGPS), i.e. maximum capacity of the electron- 
transporting system, was reached by titration of uncoupler trifluorocarbonylcyanide phenylhydrazone (FCCP; $0.05 \mu \mathrm{mol} / 1$ titration steps), ETS(S) reflecting uncoupled activity of complex II was induced by inhibition of complex I with rotenone $(0.5 \mu \mathrm{mol} / \mathrm{l})$, and ROX (residual oxygen consumption after complex III inhibition) by antimycin A $(2.5 \mu \mathrm{mol} / \mathrm{l})$. Complex IV activity was determined by simultaneous injection of N,N,N',N'-tetramethyl-p-phenylenediamine dihydrochloride (TMPD; $0.5 \mathrm{mmol} / \mathrm{l})$, and ascorbate $(2 \mathrm{mmol} / \mathrm{l})$. The oxygen consumption was analyzed on-line by DatLab software (Oroboros Instruments, Innsbruck, Austria) as negative time derivative of oxygen concentration in the chamber, expressed in pmol $\mathrm{O}_{2} /\left(\mathrm{s} .10^{6}\right.$ cells $)$ and corrected to ROX, instrumental and chemical background.

\section{Citrate synthase activity}

Mitochondrial content in the samples from each oxygraph chamber was measured by determination of the citrate synthase activity. The assay medium consisted of $0.1 \mathrm{mmol} / 1$ 5,5-dithio-bis-(2-nitrobenzoic) acid, $0.25 \%$ Triton-X, $0.5 \mathrm{mmol} / \mathrm{l}$ oxalacetate, $0.31 \mathrm{mmol} / \mathrm{l}$ acetyl coenzyme A, $5 \mu \mathrm{mo} / 1$ EDTA, $5 \mathrm{mmol} / \mathrm{l}$ triethanolamine hydrochloride, and $0.1 \mathrm{~mol} / 1$ Tris-HCl, $\mathrm{pH} 8.1$ (Kuznetsov et al. 2002). Two hundred microliters of the mixed and homogenized chamber content were added to $800 \mu \mathrm{l}$ of the medium. The enzyme activity was measured spectrophotometrically at $412 \mathrm{~nm}$ and $30^{\circ} \mathrm{C}$ over $200 \mathrm{~s}$ and expressed in mIU per $10^{6}$ cells.

\section{SOD activity}

Briefly, 10,000 HFL1 cells per well were seeded into 96-well plate and after hyperbaric exposure, the activity of enzyme was assessed by SOD determination kit according to the manufacturer's instructions. The assay is based on inhibition of reduction of the assay substrate, 2-(4-Iodophenyl)-3-(4-nitrophenyl)-5-(2,4-disulfophenyl)-2H-tetrazolium, monosodium salt (WST-1) by SOD. The absorbance was read at $450 \mathrm{~nm}$ using microplate reader Synergy H1 (Biotek, Winooski, Vermont, USA). SOD activity was calculated by the following equation: SOD activity (inhibition rate \%) = $\{[($ Ablank1 - Ablank3) - (Asample - Ablank2] / (Ablank1 - Ablank 3) $\} \times 100$.

\section{Data analysis and statistics}

Results are presented as mean \pm SD. Statistical differences were analyzed using software package OriginPro 2017 (OriginLab Corporation, Northampton,
Massachusetts, USA, 2017). After testing for the normality of distribution and homogeneity of variances, comparisons were made using Student's t-test or Mann-Whitney $U$ test where appropriate. The results were considered significantly different if $p<0.05$.

\section{Results}

\section{Cell growth}

Cells exposed to intermittent HBO displayed a trend to slower growth; however, the cell counts did not significantly differ from control cells (Fig. 1A).

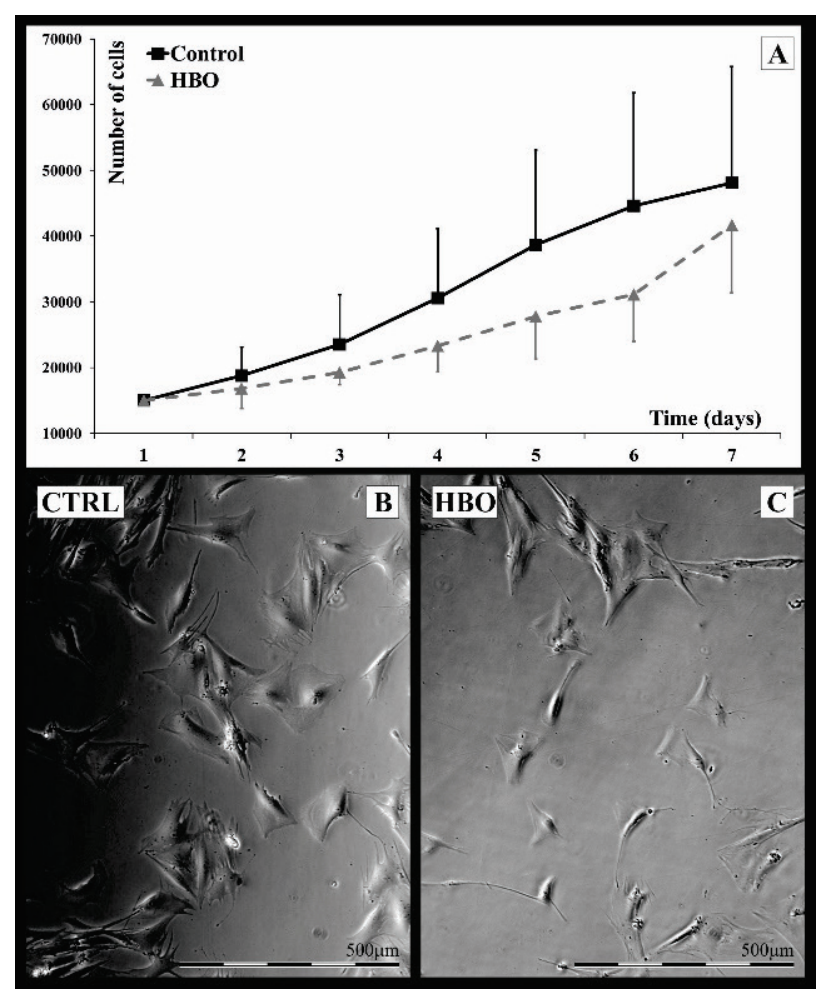

Fig. 1. HFL1 cell growth analysis and morphology. (A) Growth rate expressed in number of cells per $1 \mathrm{ml}$ did not differ between the control and HBO fibroblasts. (B, C) Phase contrast microscopic images of human fibroblasts HFL1 subjected to control (CTRL) or hyperbaric (HBO) conditions at magnification $60 \times$. All fibroblasts had spindle shape; the control cells displayed significantly larger area $\left(10,432 \pm 4,119 \mu \mathrm{m}^{2}\right)$ than HBO cells $\left(5,199 \pm 4,544 \mu \mathrm{m}^{2}\right) ; \mathrm{p}<0.001$.

\section{Cell viability}

Cell viability determined by PrestoBlue ${ }^{\circledR}$ reagent was expressed in fluorescent units (FU). For HFL1 cells exposed to HBO, we observed significantly lower signal value $(25.77 \pm 8.84 \mathrm{FU})$ compared to control cells $(34.56 \pm 9.59 \mathrm{FU})$. Higher fluorescence values correlate with greater total metabolic activity and viability $(p<0.001)$. 


\section{Cell morphology}

The phase contrast microscopy showed some differences in the cell morphology between the control and HBO group (Fig. 1B, C). All fibroblasts had spindle shape; nevertheless, the control cells occupied significantly larger area $\left(10,432 \pm 4,119 \mu \mathrm{m}^{2} \quad\right.$ vs. $5,199 \pm 1,863 \mu \mathrm{m}^{2}$ in HBO cells; $\left.\mathrm{p}<0.001\right)$, had a greater perimeter $(606 \pm 84 \mu \mathrm{m}$ vs. $506 \pm 130 \mu \mathrm{m}$ in HBO cells; $\mathrm{p}<0.001)$ and displayed slightly, but significantly higher circularity indices than $\mathrm{HBO}$ cells $(0.39 \pm 0.16$ vs. $0.28 \pm 0.12$; controls vs. HBO, respectively; $\mathrm{p}<0.001$ ).

In order to compare morphology of the cytoskeleton, fibroblasts underwent vimentin and vinculin labeling with the special antibodies and actin staining with TRITC-conjugated phalloidin. The cytoskeleton analysis mainly showed that both groups of cells had similar mesenchymal morphology without visible differences. All cells expressed vinculin-positive focal contacts distributed homogenously on the whole cell surface. HBO fibroblasts displayed smaller adhesion area than control cells, which corresponded to cell surface quantification. Nuclei of both groups of cells were mainly ellipsoidal and most of them were localized centrally. (Fig. 2A-F).

Concerning qualitative analysis of mitochondria using staining with MitoTracker, fluorescence microscopy did not reveal any apparent differences in the amount, localization of mitochondria or structure of mitochondrial networks between $\mathrm{HBO}$ and control fibroblasts. All cells had more organelles around the nuclei (Fig. 2G-H).
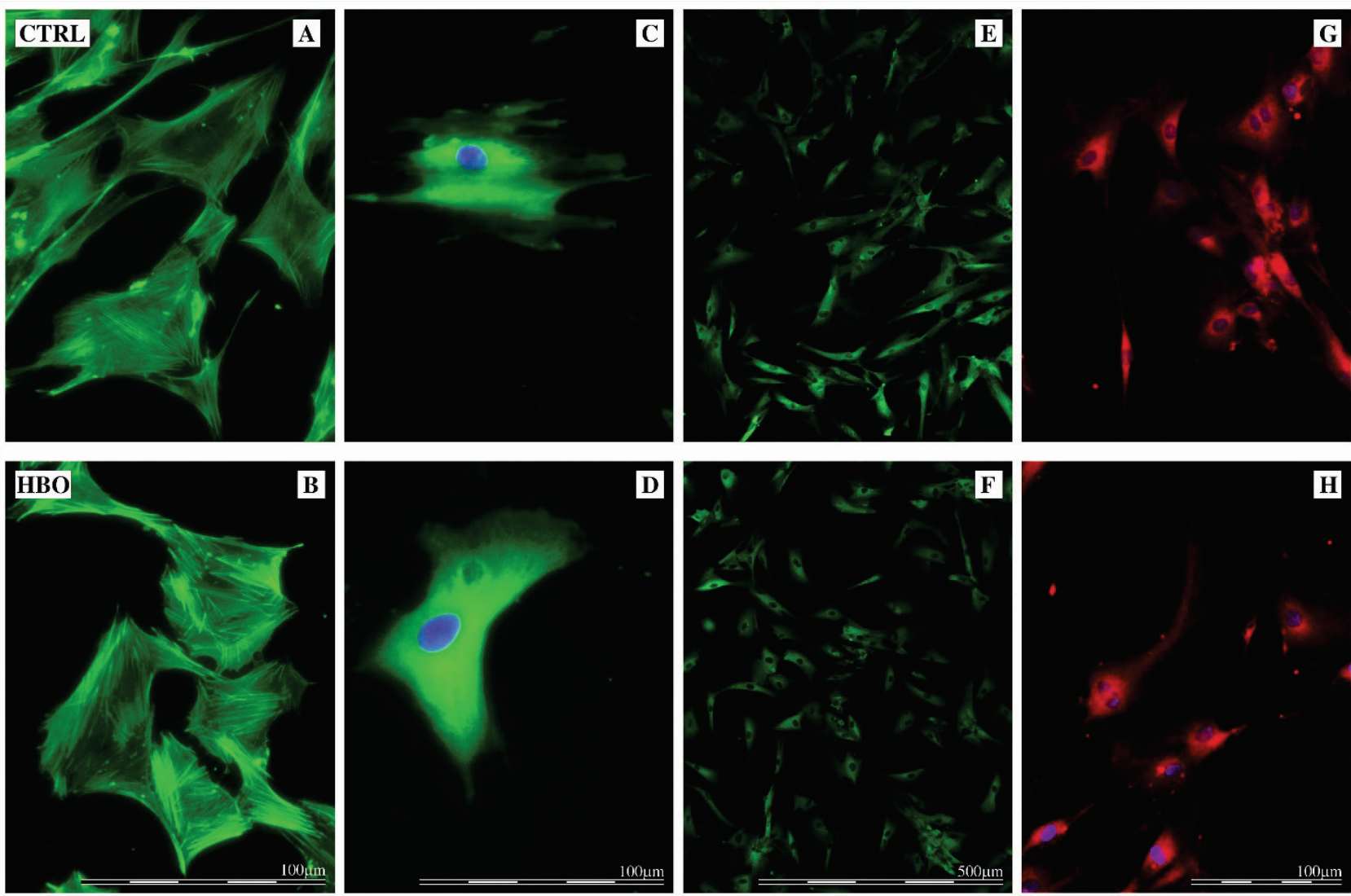

Fig. 2. Fluorescence microscopic images of human fibroblasts $H F L 1$ after 5 exposures to control $(\mathbf{A}, \mathbf{C}, \mathbf{E}, \mathbf{G})$ or hyperbaric (HBO; B, D, F, H) conditions. Visualization of focal adhesions and cytoskeleton (A-F): actin filaments (A, B; magnification 200×), vimentin (C, D; magnification 200x), vinculin (E, F; magnification 40x). The cells had normal mesenchymal morphology without visible differences. Qualitative analysis of mitochondria at magnification $160 \times(\mathrm{G}, \mathrm{H})$ did not show any apparent changes in the amount and localization of organelles or in the structure of mitochondrial networks.

\section{High-resolution respirometry}

A representative trace of the oxygen consumption in permeabilized HFL1 control cells is shown in Figure 3A. Routine respiration of intact control fibroblasts was $31.6 \pm 8.5 \mathrm{pmol} /\left(\mathrm{s} .10^{6}\right.$ cells $)$ and it did not significantly differ from the ROUT state in HBO cells $\left(35.0 \pm 13.5 \mathrm{pmol} /\left(\mathrm{s} .10^{6}\right.\right.$ cells $\left.)\right)$. State LEAK, determined after permeabilization with digitonin in the presence of 
malate and palmitoylcarnitine was significantly higher in HBO cells $\left(20.2 \pm 6.9 \mathrm{pmol} /\left(\mathrm{s} .10^{6}\right.\right.$ cells $\left.)\right)$ compared to control fibroblasts $\left(10.9 \pm 4.0 \mathrm{pmol} /\left(\mathrm{s} .10^{6}\right.\right.$ cells $\left.) ; \mathrm{p}<0.001\right)$. HBO exposure did not significantly affect states OXPHOS(Pal), OXPHOS(PalG), OXPHOS(PalGP), OXPHOS(PalGPS), ETS(PalGPS), nor CIV (Fig. 3B). State ETS(S), i.e. mitochondrial electron-transporting capacity after inhibition of complex I by rotenone, was significantly lower in HBO fibroblasts $\left(72.0 \pm 21.4 \mathrm{pmol} /\left(\mathrm{s} .10^{6} \mathrm{cells}\right)\right)$ compared to controls $\left(98.6 \pm 29.1 \mathrm{pmol} /\left(\mathrm{s} .10^{6}\right.\right.$ cells); $\left.\mathrm{p}<0.05\right) . \quad$ In addition, a number of calculated flux control ratios estimating the relative efficiency of individual interventions displayed significant differences between $\mathrm{HBO}$ and control fibroblasts (Fig. 3C). Parameter verifying increased dyscoupling of fibroblasts subjected to HBO exposure, i.e. $\mathrm{L} / \mathrm{P}$ coupling control ratio, was significantly enhanced in HBO compared to control cells $(0.42 \pm 0.16$ and $0.18 \pm 0.06$, respectively; $\mathrm{p}<0.001)$. Although total phosphorylating and electron-transporting oxygen consumptions (parameters OXPHOS(PalGPS) and ETS(PalGPS)) did not significantly differ between HBO and control fibroblasts, the excess E-P capacity determined as the difference between states ETS(PalGPS) and OXPHOS(PalGPS) was significantly lower in $\mathrm{HBO}$ cells suggesting lower limitation of OXPHOS capacity by the phosphorylation system. Capacity of mitochondria to produce ATP when metabolizing fatty acids seemed to be compromised in HBO cells, since the OXPHOS capacity (OXPHOS(Pal)) corrected for LEAK respiration was significantly lower in HBO cells $\left(30.4 \pm 17.5 \mathrm{pmol} /\left(\mathrm{s} .10^{6}\right.\right.$ cells $)$ than in control fibroblasts $\quad\left(56.8 \pm 22.8 \mathrm{pmol} /\left(\mathrm{s} .10^{6}\right.\right.$ cells $\left.) ; \quad \mathrm{p}<0.05\right)$. Respiratory reserve determined as the difference between the maximum coupled respiratory capacity, routine and leak respiration $(\mathrm{RR}=\mathrm{OXPHOS}$-ROUT-LEAK) was also significantly lower in cells exposed to HBO $\left(67.7 \pm 33.3 \mathrm{pmol} /\left(\mathrm{s} .10^{6} \mathrm{cells}\right)\right)$ compared to control fibroblasts (36.2 $\pm 19.6 \mathrm{pmol} /\left(\mathrm{s} .10^{6}\right.$ cells); p $<0.01$; Fig. 3D).

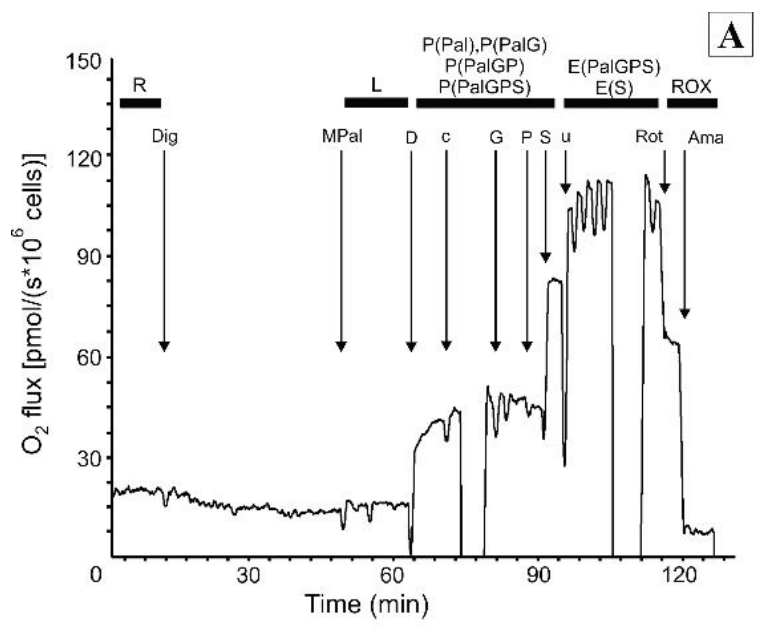

A
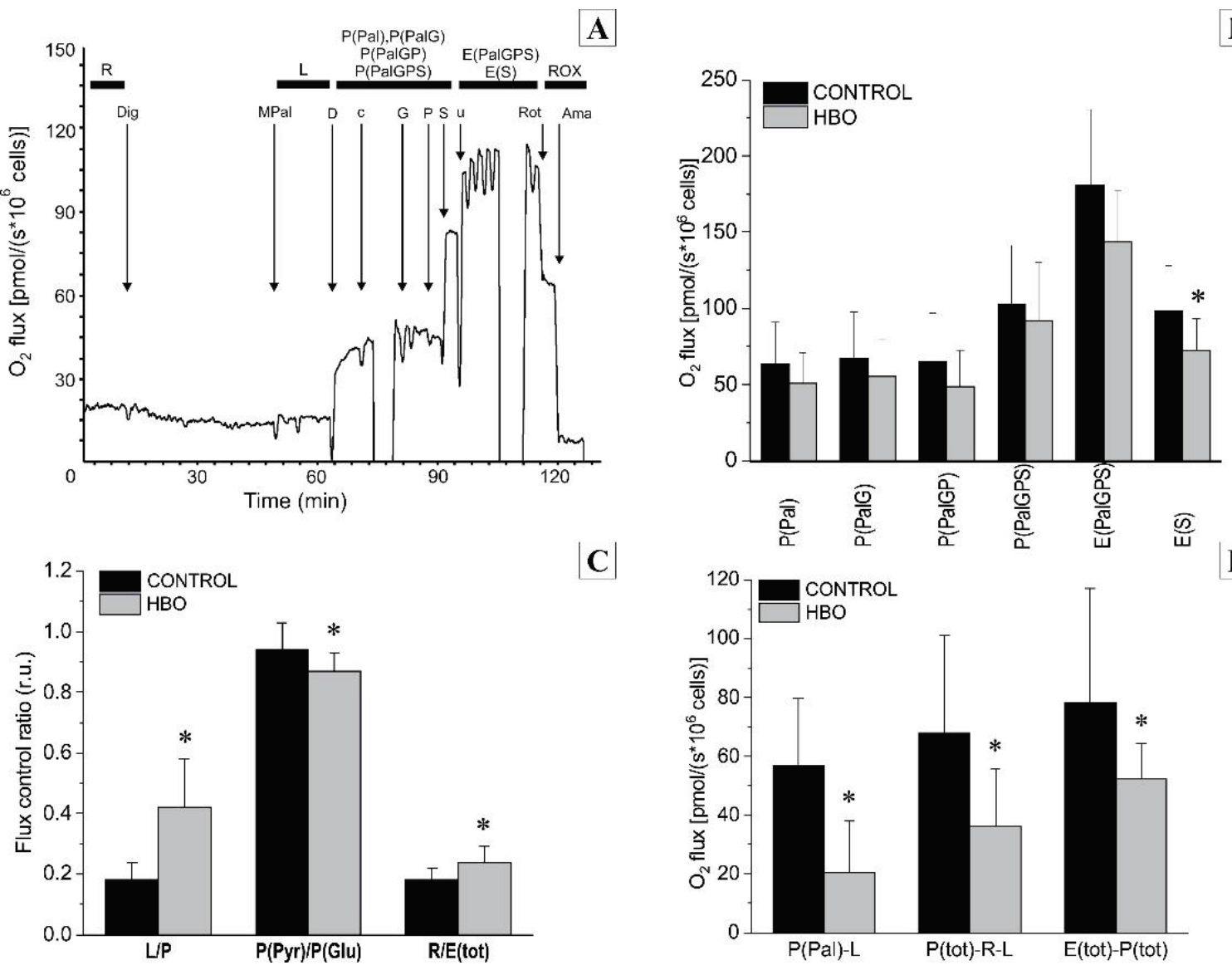

$\mid \mathbf{C}$

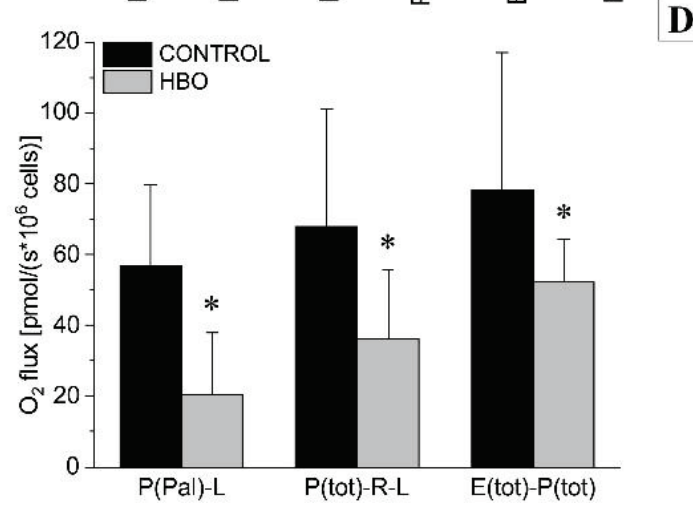

Fig. 3. Mitochondrial respiration in control and HBO-treated fibroblasts. (A) Substrate-uncoupler-inhibitor titration protocol in HFL1 cells with substrates for electron-transferring flavoprotein (ETF), complex I, and complex II. Black line=oxygen flux expressed per $10^{6}$ control cells. Dig=digitonin, $M=$ malate, $P a l=$ palmitoylcarnitine, $D=A D P, C=$ cytochrome $c, G=$ glutamate, $P=p y r u v a t e, ~ S=$ succinate, $u=F C C P$, Rot=rotenone, $A m A=$ antimycin $A$. (B) Phosphorylating $(P)$ and uncoupled (E) oxygen consumption after addition of Pal and $M$ (activity of ETF and complex I), G, P (substrates donating electrons to complex I, S (complex II substrate), and after complex I inhibition by rotenone $(E(S)$ ) showing complex II activity. (C) Flux control ratios documenting coupling state (L/P), effect of $P$ after $G(P(P y r) / P(G l u)$, and electron-transporting reserve $(R / E)$. (D) ATP-related oxygen consumption $(P(P a l)-L)$, respiratory reserve $(P($ tot $)-R-L)$ and excess E-P capacity (see text). 


\section{Citrate synthase activity}

In the control fibroblasts, citrate synthase activity was $126 \pm 36 \mathrm{mIU} / 10^{6}$ cells and it was not significantly affected by intermittent exposure to $\mathrm{HBO}$ $\left(124 \pm 57 \mathrm{mIU} / 10^{6}\right.$ cells $)$ suggesting that HBO $\mathrm{did}$ not affect mitochondrial quantity in HFL1 cells.

\section{SOD activity}

SOD activity, expressed as inhibition rate of reduction of the assay substrate WST-1, was significantly higher in HBO cells (20.6 $\pm 2.7 \%)$ compared to controls $(14.7 \pm 2.5 \%$; $<<0.001)$.

\section{Discussion}

The present study describes the effects of repeated exposure to $\mathrm{HBO}$ on mitochondrial structure, density, and oxygen consumption in human lung fibroblasts in relation to cellular antioxidant capacity, proliferation, and morphology.

Parameters of HBO exposure were selected according to approved therapeutic limits recommending maximum oxygen pressure 3 ATA (approx. $300 \mathrm{kPa}$ ) and $2 \mathrm{~h}$ duration (Ay et al. 2007). The number of HBO sessions used in clinical medicine has not been firmly standardized as it substantially depends on the given medical condition; it could range from several to 60 sessions (Mathieu et al. 2017). In animal experiments, the number of HBO exposures usually ranges between 1 and 15 (Ay et al. 2007, Ding et al. 2017, Limirio et al. 2018, Sun et al. 2017); studies on HBO impact on ex vivo models using various cell types usually report from 1 to 7 HBO exposures (Kang et al. 2004) and document that the effect of treatment is detectable even after a single exposure. For our experiments we have thus selected conditions mimicking chronic HBO treatment on the cellular model.

The major finding of our study is the effect of HBO on some parameters of mitochondrial oxygen consumption, particularly on the leak respiration and oxygen consumption related to the activity of respiratory complex II.

Mitochondrial state LEAK is oxygen consumption compensating for proton leak, proton slip, electron leak, and cation cycling (Gnaiger 2014). It reflects mitochondrial coupling efficiency and production of reactive oxygen species (ROS; Jastroch et al. 2010) and may account for $38 \%$ of the basal metabolic rate in mammals (Brand et al. 1994). Superoxide anion $\left(\mathrm{O}_{2}{ }^{-}\right)$is the primary ROS formed by the electron transport chain particularly due to electron leak when a single electron is transferred to oxygen molecule (Jastroch et al. 2010). Superoxide generated mainly by the respiratory complexes I and III is then converted into hydrogen peroxide by SODs, major antioxidant defense systems against $\mathrm{O}_{2}{ }^{-}$(Fukai and Ushio-Fukai 2011). It has been well documented that ROS production increases in HBO conditions, although oxidative susceptibility varies with the cell type, parameters of HBO therapy and number of exposures (Jang et al. 2018, Korkmaz et al. 2008, Simsek et al. 2011). Literature data on SOD activity in HBO-treated subjects frequently document its increase going either in parallel with elevated ROS production and markers of oxidative stress (Simsek et al. 2011) or fully compensating for oxidative damage (Sun et al. 2017). In our study, mitochondrial LEAK state, L/P coupling control ratio, and SOD activity significantly increased in fibroblasts subjected to HBO treatment suggesting that increased formation of superoxide anion could contribute to elevated leak respiration.

All parameters associated with the potential ability of the cells to increase oxygen consumption and ATP synthesis, i.e. excess E-P capacity, respiratory reserve determined as total OXPHOS capacity corrected for routine and leak respiration or free OXPHOS capacity, i.e. OXPHOS capacity corrected for leak respiration (Gnaiger 2014), were significantly lower in HBO-exposed cells compared to controls suggesting compromised capability of HBO fibroblasts to cope with metabolic needs during energy demanding processes like growth and division. Accordingly, parameters quantifying the whole cell morphology as area, perimeter and circularity were all significantly lower in HBO cells than in controls. As the cell counts did not significantly differ between HBO and control conditions in the end of experiment, the viability test quantifying reduction of the non-fluorescent resazurin to the fluorescent resorufin by the mitochondrial and cytoplasmic enzymes also indicated impaired cellular metabolism after repeated HBO exposure (Zalata et al. 1998). HBO treated cells were apparently smaller than untreated fibroblasts; this finding could imply that decreased fluorescent signal in viability test was related to the total area of tested cells; however, citrate synthase activity, marker of mitochondrial quantity was nearly identical in both experimental groups. Moreover, any visible differences in the amount of mitochondria or structure of mitochondrial networks between $\mathrm{HBO}$ and control fibroblasts were not 
revealed by fluorescence microscopy. It is thus probable that the total reducing capacity of the cell was compromised by excessive oxygen load in HBO conditions.

Decreased complex II activity revealed in HBO-treated cells could have several interesting implications. Respiratory complex II is the only common component coupling the tricarboxylic acid cycle to the mitochondrial electron transport system. It has been suggested that fully assembled complex II could be a source of the reserve respiratory capacity in response to various metabolic sensors, like AMP-dependent kinase or pyruvate dehydrogenase (PDH) via sirtuin-3-dependent mechanism (Pfleger et al. 2015). Neither PDH activity nor its expression were analyzed in our study; however, pyruvate effect was determined in the SUIT respirometric protocol. Pyruvate had slight, but significant inhibitory effect on mitochondrial oxygen consumption induced by substrates of ETF and complex I, i.e. malate, palmitoylcarnitine, and glutamate, as shown in ratio OXPHOS(PalGP)/OXPHOS(PalG) that was lower in HBO cells compared to control fibroblasts. This phenomenon is known to be mediated by $\mathrm{PDH}$ that changes its activity in response to fatty acid oxidation (Chicco et al. 1991, Kelley et al. 1993, Scholz et al. 1978) and is regulated by PDH kinases (Pfleger et al. 2015). It has been reported that stimulation of PDH through inactivation of PDK by dichloroacetate could significantly increase not only complex I-related oxygen consumption, but also complex II activity. Taken together, our results indicate that HBO conditions could interfere with regulation of mitochondrial respiration through partial inhibition of complex II activity. It has been documented that complex II could modulate generation of superoxide by other complexes of electron transport system and its activity could be inhibited by hydrogen peroxide (Dröse et al. 2011, Nulton-Persson and Szweda 2001). In turn, inhibition of complex II might be involved in the protection against oxidative stress in various pathological conditions (Adebiyi et al. 2008, Jodeiri Farshbaf and Kiani-Esfahani 2017, Wojtovich et al. 2009).

In conclusion, the present study shows that repeated exposure of the lung fibroblasts to HBO resulted in the impaired mitochondrial oxygen consumption manifested by increased leak respiration, decreased activity of complex II and compromised ATP-related oxygen consumption when fatty acids are oxidized. Underlying mechanism of this HBO-induced mitochondrial dysfunction should be further explored; however, the data suggest that it might be related to the cellular protection against oxidative stress.

\section{Study limitations}

In this study, we have used human pulmonary fibroblasts, i.e. cells from the tissue reported as extremely vulnerable to oxygen (Han et al. 2018). However, it is not clear, which cell type in the lungs is primarily affected by oxygen toxicity. In addition, intact fetal cells that were not previously challenged by any pathology associated with the clinical need for HBO therapy (e.g. carbon monoxide poisoning) were used in our experiments. The effect of HBO could be also cell- and age-dependent (Gomez et al. 2012, Tolentino et al. 2006).

Detailed analysis of RONS production or the expression of their putative molecular targets, like nuclear factor $\kappa \mathrm{B}$, heat shock protein 90 or protein involved in the regulation of apoptosis Bcl-2 were not performed in our study (Yogaratnam et al. 2010). As there is increasing evidence that RONS are involved in a number of physiological cell signaling pathways (Shadel and Horvath 2015), a study addressing redox signaling under hyperoxic conditions would bring new insights into the potentially beneficial or harmful effects of HBO at the subcellular level.

Although normoxia is often referred as oxygen tension in ambient atmosphere, oxygen tension in tissues may vary between 1 and $7 \mathrm{kPa}$. Only the lung tissue is exposed to nearly atmospheric $\mathrm{pO}_{2}(15 \mathrm{kPa})$. In our study, oxygen tension in the cell culture was not directly measured; however approximation based on the $\mathrm{pO}_{2}$, $\mathrm{pCO}_{2}$ and height of the layer of the cell culture medium suggests that $\mathrm{pO}_{2}$ under normoxic conditions approached desired physiological values (Wenger et al. 2015).

\section{Conflict of Interest}

There is no conflict of interest.

\section{Acknowledgements}

The study was supported by the Charles University Research Fund (Progres Q39), by the National Sustainability Program I (NPUI) Nr. LO1503 provided by the MEYS CR, project No. CZ.02.1.01/ 0.0/0.0/16_019/0000787 „Fighting INfectious Diseases“, awarded by the MEYS CR, financed from EFRR, and the Specific Student Research Project no. 260394/2017 of the Charles University in Prague. 


\section{References}

ADEBIYI A, MCNALLY EM, JAGGAR JH: Sulfonylurea receptor-dependent and -independent pathways mediate vasodilation induced by ATP-sensitive K+ channel openers. Mol Pharmacol 74: 736-743, 2008.

AY H, TOPAL T, UYSAL B, OZLER M, OTER S, KORKMAZ A, DÜNDAR K: Time-dependent course of hyperbaric oxygen-induced oxidative effects in rat lung and erythrocytes. Clin Exp Pharmacol Physiol 34: 787-791, 2007.

BASSETT DJ, FISHER AB: Glucose metabolism in rat lung during exposure to hyperbaric O2. J Appl Physiol Respir Environ Exerc Physiol 46: 943-949, 1979.

BENNETT MH, KERTESZ T, PERLETH M, YEUNG P, LEHM JP: Hyperbaric oxygen for idiopathic sudden sensorineural hearing loss and tinnitus. Cochrane Database Syst Rev 10: CD004739, 2012.

BORAB Z, MIRMANESH MD, GANTZ M, CUSANO A, PU LL: Systematic review of hyperbaric oxygen therapy for the treatment of radiation-induced skin necrosis. J Plast Reconstr Aaesthet Surg 70: 529-538, 2017.

BRAND MD, CHIEN LF, AINSCOW EK, ROLFE DF, PORTER RK: The causes and functions of mitochondrial proton leak. Biochim Biophys Acta 1187: 132-139, 1994.

BREM H, TOMIC-CANIC M: Cellular and molecular basis of wound healing in diabetes. $J$ Clin Invest 117: 1219-1222, 2007.

BUCKLEY NA, JUURLINK DN, ISBISTER G, BENNETT MH, LAVONAS EJ: Hyperbaric oxygen for carbon monoxide poisoning. Cochrane Database Syst Rev 4: CD002041, 2011.

CAMPORESI EM, BOSCO G: Mechanisms of action of hyperbaric oxygen therapy. Undersea Hyperb Med 41: 247-252, 2014.

CHICCO A, GUTMAN R, LOMBARDO YB: Biochemical abnormalities in the heart of rats fed a sucrose-rich diet: is the low activity of the pyruvate dehydrogenase complex a result of increased fatty acid oxidation? Metabolism 40: 15-21, 1991.

DING P, REN D, HE S, HE M, ZHANG G, CHEN Y, SANG H, PENG Z, YAN W: Sirt1 mediates improvement in cognitive defects induced by focal cerebral ischemia following hyperbaric oxygen preconditioning in rats. Physiol Res 66: 1029-1039, 2017.

DRÖSE S, BLEIER L, BRANDT U: A common mechanism links differently acting complex II inhibitors to cardioprotection: modulation of mitochondrial reactive oxygen species production. Mol Pharmacol 79: 814-822, 2011.

FUKAI T, USHIO-FUKAI M: Superoxide dismutases: role in redox signaling, vascular function, and diseases. Antioxid Redox Signal 15: 1583-1606, 2011.

GNAIGER E: Mitochondrial pathways and respiratory control. Oroboros MiPNet Publications, Innsbruck 2014: (4th ed.) 81, 2014.

GOMEZ CR, KNUTSON GJ, CLIFTON KB, SCHREIBER CA, VUK-PAVLOVIĆ S: Age-dependent response of murine female bone marrow cells to hyperbaric oxygen. Biogerontology 13: 287-297, 2012.

HAN CH, GUAN ZB, ZHANG PX, FANG HL, LI L, ZHANG HM, ZHOU FJ, MAO YF, LIU WW: Oxidative stress induced necroptosis activation is involved in the pathogenesis of hyperoxic acute lung injury. Biochem Biophys Res Commun 495: 2178-2183, 2018.

HAN G, LIU K, LI L, LI X, ZHAO P: The effects of hyperbaric oxygen therapy on neuropathic pain via mitophagy in microglia. Mol Pain 13: 1744806917710862, 2017.

HOLUBOVA M, LEBA M, SEDMIKOVA M, VANNUCCI L, HORAK V: Characterization of three newly established rat sarcoma cell clones. In Vitro Cell Dev Biol Anim 48: 610-618, 2012.

HUANG CC, HO CH, CHEN YC, LIN HJ, HSU CC, WANG JJ, SU SB, GUO HR: Hyperbaric oxygen therapy is associated with lower short- and long-term mortality in patients with carbon monoxide poisoning. Chest 152: 943-953, 2017.

JANG DH, KHATRI UG, SHORTAL BP, KELLY M, HARDY K, LAMBERT DS, ECKMANN DM: Alterations in mitochondrial respiration and reactive oxygen species in patients poisoned with carbon monoxide treated with hyperbaric oxygen. Intensive Care Med Exp 6: 4, 2018. 
JASTROCH M, DIVAKARUNI AS, MOOKERJEE S, TREBERG JR, BRAND MD: Mitochondrial proton and electron leaks. Essays Biochem 47: 53-67, 2010.

JODEIRI FARSHBAF M, KIANI-ESFAHANI A: Succinate dehydrogenase: prospect for neurodegenerative diseases. Mitochondrion 42: 77-83 2017.

KANG TS, GORTI GK, QUAN SY, HO M, KOCH RJ: Effect of hyperbaric oxygen on the growth factor profile of fibroblasts. Arch Facial Plast Surg 6: 31-35, 2004.

KELLEY DE, MOKAN M, SIMONEAU JA, MANDARINO LJ: Interaction between glucose and free fatty acid metabolism in human skeletal muscle. J Clin Invest 92: 91-98, 1993.

KORKMAZ A, OTER S, SADIR S, TOPAL T, UYSAL B, OZLER M, AY H, AKIN A: Exposure time related oxidative action of hyperbaric oxygen in rat brain. Neurochem Res 33: 160-166, 2008.

KUZNETSOV AV, STROBL D, RUTTMANN E, KÖNIGSRAINER A, MARGREITER R, GNAIGER E: Evaluation of mitochondrial respiratory function in small biopsies of liver. Anal Biochem 305: 186-194, 2002.

LIMIRIO PHJO, DA ROCHA JUNIOR HA, MORAIS RB, HIRAKI KRN, BALBI APC, SOARES PBF, DECHICHI P: Influence of hyperbaric oxygen on biomechanics and structural bone matrix in type 1 diabetes mellitus rats. PloS One 13: e0191694, 2018.

LIN SS, UENG SW, NIU CC, YUAN LJ, YANG CY, CHEN WJ, LEE MS, CHEN JK: Hyperbaric oxygen promotes osteogenic differentiation of bone marrow stromal cells by regulating Wnt3a/ $\beta$-catenin signaling-an in vitro and in vivo study. Stem Cell Res 12: 260-274, 2014.

MATHIEU D, MARRONI A, KOT J: Correction to Mathieu D, Marroni A, Kot J: Tenth European Consensus Conference on Hyperbaric Medicine: recommendations for accepted and non-accepted clinical indications and practice of hyperbaric oxygen treatment. Diving Hyperb Med 47: 131-132, 2017.

MATSUNAMI T, SATO Y, SATO T, ARIGA S, SHIMOMURA T, YUKAWA M: Oxidative stress and gene expression of antioxidant enzymes in the streptozotocin-induced diabetic rats under hyperbaric oxygen exposure. Int J Clin ExpPathol 30: 177-188, 2009.

MCMONNIES CW: Hyperbaric oxygen therapy and the possibility of ocular complications or contraindications. Clin Exp Optom 98: 122-125, 2015.

MOON RE: Hyperbaric oxygen treatment for decompression sickness. Undersea Hyperb Med 41: 151-157, 2014.

NG AWA, MULLER R, ORTON J: Incidence of middle ear barotrauma in staged versus linear chamber compression during hyperbaric oxygen therapy: a double blinded, randomized controlled trial. Undersea Hyperb Med 44: 101-107, 2017.

NIU CC, LIN SS, YUAN LJ, CHEN LH, WANG IC, TSAI TT, LAI PL, CHEN WJ: Hyperbaric oxygen treatment suppresses MAPK signaling and mitochondrial apoptotic pathway in degenerated human intervertebral disc cells. J Orthop Res 31: 204-209, 2013.

NULTON-PERSSON AC, SZWEDA LI: Modulation of mitochondrial function by hydrogen peroxide. $J$ Biol Chem 276: 23357-23361, 2001.

PATEL NP, HUANG JH: Hyperbaric oxygen therapy of spinal cord injury. Med Gas Res 7: 133-143, 2017.

PESTA D, GNAIGER E: High-resolution respirometry: OXPHOS protocols for human cells and permeabilized fibers from small biopsies of human muscle. Methods Mol Biol 810: 25-58, 2012.

PFLEGER J, HE M, ABDELLATIF M: Mitochondrial complex II is a source of the reserve respiratory capacity that is regulated by metabolic sensors and promotes cell survival. Cell Death Dis 6: e1835, 2015.

POFF AM, KERNAGIS D, D'AGOSTINO DP: Hyperbaric environment: oxygen and cellular damage versus protection. Compr Physiol 7: 213-234, 2016.

RABRENOVIĆ M, TREŠNJIĆ S, RABRENOVIĆ V, ČIKIRIZ N, MAŠIĆ S, MATUNOVIĆ R: Neurotoxic effects of oxygen in hyperbaric environment: A case report. Vojnosanit Pregl 72: 827-830, 2015.

RIVALLAND G, MITCHELL SJ, VAN SCHALKWYK JM: Pulmonary barotrauma and cerebral arterial gas embolism during hyperbaric oxygen therapy. Aviat Space Environ Med 81: 888-890, 2010.

SHADEL GS, HORVATH TL: Mitochondrial ROS signaling in organismal homeostasis. Cell 163: 560-569, 2015.

SCHOLZ R, OLSON MS, SCHWAB AJ, SCHWABE U, NOELL C, BRAUN W: The effect of fatty acids on the regulation of pyruvate dehydrogenase in perfused rat liver. Eur J Biochem 86: 519-530, 1978. 
SCHREML S, SZEIMIES RM, PRANTL L, KARRER S, LANDTHALER M, BABILAS P: Oxygen in acute and chronic wound healing. Br J Dermatol 163: 257-268, 2010.

SIMSEK K, AY H, TOPAL T, OZLER M, UYSAL B, UCAR E, ACIKEL CH, YESILYURT O, KORKMAZ A, OTER S, YILDIZ S: Long-term exposure to repetitive hyperbaric oxygen results in cumulative oxidative stress in rat lung tissue. Inhal Toxicol 23: 166-172, 2011.

SUN Y, LIU D, WANG Q, SU P, TANG Q: Hyperbaric oxygen treatment of spinal cord injury in rat model. BMC Neurol 17: 128, 2017.

TOLENTINO EC, CASTRO E SILVA O, ZUCOLOTO S, SOUZA MEJ, GOMES MCJ, SANKARANKUTTY AK, OLIVEIRA GR, FERES O: Effect of hyperbaric oxygen on liver regeneration in a rat model. Transplant Proc 38: 1947-1952, 2006.

WENGER RH, KURTCUOGLU V, SCHOLZ CC, MARTI HH, HOOGEWIJS D: Frequently asked questions in hypoxia research. Hypoxia (Auckl) 3: 35-43, 2015.

WILKINSON D, DOOLETTE D: Hyperbaric oxygen treatment and survival from necrotizing soft tissue infection. Arch Surg 139: 1339-1345, 2004.

WOJTOVICH AP, BROOKES PS: The complex II inhibitor atpenin A5 protects against cardiac ischemia-reperfusion injury via activation of mitochondrial KATP channels. Basic Res Cardiol 104: 121-129, 2009.

YANG Z, HU J, QU Y, SUN F, LENG X, LI H, ZHAN S: Interventions for treating gas gangrene. Cochrane Database Syst Rev 12: CD010577, 2015.

YOGARATNAM JZ, LADEN G, GUVENDIK L, COWEN M, CALE A, GRIFFIN S: Hyperbaric oxygen preconditioning improves myocardial function, reduces length of intensive care stay, and limits complications post coronary artery bypass graft surgery. Cardiovasc Revasc Med 11: 8-19, 2010.

ZALATA AA, LAMMERTIJN N, CHRISTOPHE A, COMHAIRE FH: The correlates and alleged biochemical background of the resazurin reduction test in semen. Int J Androl 21: 289-294, 1998.

ZHAO D, LUO S, XU W, HU J, LIN S, WANG N: Efficacy and safety of hyperbaric oxygen therapy used in patients with diabetic foot: a meta-analysis of randomized clinical trials. Clin Ther 39: 2088-2094.e2, 2017. 